\title{
Antidiabetic Efficacy of Nigella sativa Linn. in Alloxan-induced Diabetic Rabbits
}

\author{
Ikram $\mathrm{F}^{\mathrm{a}}$, Hussain $\mathrm{F}^{\mathrm{b}}$ \\ ${ }^{a}$ Department of Chemistry and Biochemistry, Faculty of Sciences, University of Agriculture, Faisalabad, Pakistan \\ ${ }^{b}$ Department of Chemistry and Biochemistry, Faculty of Sciences, University of Agriculture, Faisalabad, Pakistan
}

\begin{abstract}
Introduction: Diabetes mellitus (DM) is the most common metabolic disease worldwide. Multiple medications and side effects, the most significant and prevalent themes in diabetes mellitus ultimately determine novel directions and avenues in drug discovery. The present study was conducted to investigate antidiabetic efficacy of extracts of Nigella sativa Linn. seeds (NS). Methods: Alloxan-induced diabetic rabbits $(n=28)$ were divided into four groups, including diabetic control. Two groups were treated with NS methanol (NSM) and ethanol (NSE) extracts, and one group were given glibenclamide. Serum glucose, triglyceride (TG), total cholesterol (TC), high-density lipoprotein cholesterol (HDL-C), low-density lipoprotein cholesterol (LDL-C) and very low-density lipoprotein cholesterol (VLDL-C) were measured by kit methods. Results: NS demonstrated hypoglycaemic and hypolipidaemic activities. Although NS treatments decreased blood glucose, TC, TG and LDL-C and increased $\mathrm{HDL}-\mathrm{C}$ in diabetic groups, it was unable to normalize all the parameters. NS extracts did not regenerate $B$-cells of islet of the pancreas. Glibenclamide showed significant $(P<0.05)$ decline in hyperglycaemia and hyperlipidaemia as well as prominent renewal of B-cells of islets of Langerhans. Few surviving beta cells of islet of the pancreas were apparent in NSM treated group. Standard drug glibenclamide showed a significant decline in hyperglycaemia and hyperlipidaemia as well as prominent renewal of beta cells. Conclusion: N. sativa L. extracts have curative effects in terms of diabetes-induced disturbances of glucose and lipids. Further investigations are suggested to ascertain the therapeutic role of NS on islet histopathology in diabetes mellitus.
\end{abstract}

KEYWORDS: Diabetes mellitus, glibenclamide, hypoglycaemia, Nigella sativa Linn.

\section{INTRODUCTION}

Diabetes mellitus (DM) is the most common metabolic disease worldwide. Therapeutic compounds available to treat DM are either synthetic or formulated forms. Multiple medications and side effects, the most significant and prevalent themes in DM ultimately determine novel directions and avenues in drug discovery. Therefore, a variety of plants are used in the management and treatment of DM. Chemical and pharmacological studies on antidiabetic herbal remedies are in progress and might lead to inspiring elucidations. ${ }^{1}$ Nigella sativa Linn. (Ranunculaceae) seeds (NS) known as "black seed" or "black cumin" are commonly used in traditional medication systems. ${ }^{2,3,4}$ Antioxidant and anti-inflammatory actions of NS are already

\footnotetext{
Corresponding author:

Dr. Fatma Hussain, Department of Chemistry and Biochemistry, Faculty of Sciences, University of Agriculture, Faisalabad-38040, Pakistan. Phone: +92-41-9200161-170, Ext. 3313, E-mail: fatmauaf@yahoo.com
}

acknowledged. 5,6,7 Salutary characteristics of NS in the management of hyperglycemia, hyperlipidemia and bronchial asthma were cited previously. $8,9,10,11$ NS also possess chemo-preventive and insulinotropic effects. ${ }^{12,13,14,15,16}$

In view of the established antidiabetic potentials, present study was performed to investigate antidiabetic efficacy of NS and to compare it with that of glibenclamide (glyburide), a reference antidiabetic drug. Glibenclamide enhances insulin secretion from islet cells and thus promotes hypoglycaemia and hypolipidaemia.

\section{MATERIALS \& METHODS}

Nigella sativa seeds were collected from local retail market and authenticated at the Department of Botany, University of Agriculture, Faisalabad, Pakistan. After washing and drying, seeds were ground into a fine powder state. NS $(50 \mathrm{~g})$ was homogenized with $150 \mathrm{ml}$ methanol and ethanol separately and kept on an orbital shaker $(120 \mathrm{rpm})$ for 48 hours at room temperature. Mixtures were filtered and concentrated at $50^{\circ} \mathrm{C}$ in water bath. The final yields were $5.7 \%$ and $3.6 \%$ for NS methanolic (NSM) and ethanol (NSE) extracts respectively. The suspensions of these extracts were then prepared in $0.5 \% \mathrm{w} / \mathrm{v}$ carboxymethylcellulose 
(CMC) in normal saline solution.

Healthy male rabbits (Oryctolagus cuniculus) weighing 1-1.5 kg were kept in metal cages with free access to standard feed and water ad libitum. The animals were acclimatized to the laboratory conditions prior to experimentation in the animal house of the Institute of Microbiology, Faculty of Veterinary Sciences, University of Agriculture, Faisalabad. Alloxan monohydrate (Sigma-Aldrich) was used ( 80 $\mathrm{mg} / \mathrm{kg}$ body weight) through intravenous injection to ear vein. Rabbits having fasting blood glucose levels greater than $150 \mathrm{mg} / \mathrm{dL}$ were considered diabetics. Group 1 was the vehicle (seven healthy rabbits as negative control). The overnight fasted animals were randomly divided into four groups (seven animals per group). These groups were, Group 2: Diabetic control (diabetic rabbits as positive control), Group 3: Diabetic rabbits for oral administration of $100 \mathrm{mg} / \mathrm{kg}$ body weight NS methanol extract, Group 4: Diabetic rabbits for oral administration of $100 \mathrm{mg} / \mathrm{kg}$ body weight NS ethanol extract, Group 5: Diabetic rabbits for oral administration of glibenclamide $(2.5 \mathrm{mg} / \mathrm{kg}$ body weight).

All the groups were loaded with glucose solution (2.0 $\mathrm{g} / \mathrm{kg}$ ) intravenously after half an hour of extract/drug administration. Extract/drug treatment continued for two weeks. Fasting blood samples were collected at baseline and after treatment. Serum glucose, triglycerides (TG), total Cholesterol (TC), HDLCholesterol (HDL-C) was measured by kit methods (Ecoline Diasys GmbH Merck, Germany). LDL-C concentrations were calculated as: Total cholesterol - HDL.C- VLDL.C. ${ }^{17}$ Whereas, VLDL-Cholesterol was calculated as: Triglyceride/5.18

\section{RESULTS}

\section{Hypoglycaemic Effects:}

Alloxan monohydrate raised the blood-glucose levels up to $265.6 \pm 30.26 \mathrm{mg} / \mathrm{dL}$. Blood glucose was significantly higher $(265.6 \pm 30.26 \mathrm{mg} / \mathrm{dL} ; \mathrm{P}<0.05)$ in diabetic rabbits as compared to non-diabetic rabbits $(99.5 \pm 13.12 \mathrm{mg} / \mathrm{dL})$. Glucose levels in NS treated groups (Diabetic + NSM and Diabetic + NSM) showed descending trends in the post-treatment analysis. However, lowered glucose levels were higher (Diabetic + NSM: $176.6 \pm 26.75 \mathrm{mg} / \mathrm{dL}$; Diabetic + NSE: $205.3 \pm$ $31.12 \mathrm{mg} / \mathrm{dL}$ ) than that of the vehicle (non-diabetic control group: $104.7 \pm 13.23 \mathrm{mg} / \mathrm{dL}$ ). NSM and NSE treatment made $32.64 \%$ and $22.87 \%$ change $(P<0.05)$ in glucose as compared to the initial levels (Table 1 ). This reflected significant $(P<0.05)$ hypoglycemic effect in NS treated rabbits as compared to the diabetic group. Nonetheless, final glucose levels were higher (Diabetic + NSM: $176.6 \pm 26.75 \mathrm{mg} / \mathrm{dL}$; Diabetic + NSE: $205.3 \pm$ $31.12 \mathrm{mg} / \mathrm{dL})$ than that of the vehicle $(104.7 \pm 13.23$ $\mathrm{mg} / \mathrm{dL}$ ). Glibenclamide not only reduced the glucose level by $58 \%$ as compared to baseline concentrations, it also attained the normal range. NS managed to lower hyperglycemia, but it was less effective than glibenclamide.

Table 1. Effects of treatment with N. sativa seed extracts on serum glucose and lipids in alloxan diabetic rabbits

\begin{tabular}{lllllll}
\hline \multicolumn{6}{c}{ Study Groups } \\
\cline { 3 - 6 } & & & \multicolumn{5}{c}{ Vehicle } & Diabetic & Diabetic + NSM & Diabetic + NSE & Diabetic + G \\
\cline { 3 - 7 } & & & & & \\
Glucose & Initial & $99.5 \pm 13.12$ & $265.6 \pm 30.26$ & $262.2 \pm 29.45$ & $266.1 \pm 39.47$ & $265.4 \pm 24.39$ \\
& Final & $104.7 \pm 13.23$ & $296.3 \pm 45.91$ & $176.6 \pm 26.75^{*}$ & $205.3 \pm 31.12^{*}$ & $111.3 \pm 19.18^{*}$ \\
TG & Initial & $88.19 \pm 5.19$ & $154.66 \pm 7.6$ & $158.44 \pm 9.01$ & $152.22 \pm 8.93$ & $159.74 \pm 9.25$ \\
& Final & $89.15 \pm 6.37$ & $166.81 \pm 4.33$ & $134.31 \pm 10.0^{*}$ & $146.03 \pm 10.5$ & $78.32 \pm 5.7^{*}$ \\
TC & Initial & $53.14 \pm 10.58$ & $200.33 \pm 5.01$ & $194.21 \pm 7.26$ & $197.09 \pm 7.9$ & $199.25 \pm 6.38$ \\
& Final & $54.67 \pm 7.64$ & $210.2 \pm 4.77$ & $177.15 \pm 1.69^{*}$ & $186.42 \pm 4.17$ & $123.75 \pm 2.80^{*}$ \\
HDL-C & Initial & $28.66 \pm 3.7$ & $45.33 \pm 8.5$ & $42.55 \pm 2.95$ & $46.41 \pm 1.97$ & $43.7 \pm 2.85$ \\
& Final & $27.99 \pm 7.21$ & $43.86 \pm 3.65$ & $43.11 \pm 1.6$ & $47.98 \pm 3.70$ & $51.54 \pm 1.67^{*}$ \\
LDL-C & Initial & $6.85 \pm 1.92$ & $124.07 \pm 2.2$ & $119.98 \pm 2.62$ & $120.2 \pm 3.64$ & $123.61 \pm 2.99$ \\
& Final & $8.85 \pm 5.61$ & $132.98 \pm 0.99$ & $107.18 \pm 1.91^{*}$ & $109.24 \pm 1.82^{*}$ & $56.55 \pm 2.97^{*}$ \\
& & & & & & \\
\hline
\end{tabular}

Data expressed as mean $(\mathrm{mg} / \mathrm{dL}) \pm \mathrm{SEM}$ of triplicate measurements for groups of seven animals each. ${ }^{*} \mathrm{P}<0.05$ as compared to diabetic control.

TG: triglyceride; TC: total cholesterol; Diabetic + NSM: Diabetic group given NS methanol extract; Diabetic + NSE: Diabetic group given NS ethanol extract; Diabetic + G: Diabetic group given glibenclamide. 
Hypolipidaemic Effects:

Hypolipidaemic activity of NS is summarized in Table 1. Significantly higher $(P<0.05)$ levels of $T C, T G, L D L-C$ and $\mathrm{HDL}-\mathrm{C}$ in diabetic animals as that of vehicle control were observed at baseline. NS exhibited trivial antihypercholesterolemic and antihypertriglyceridemic activities in NS groups (Diabetic + NSM and Diabetic + NSM). NSM extracts accomplished 15\% reduction $(\mathrm{P}<0.05)$ in TG but was ineffective to reach normal range that was accomplished with glibenclamide $(51 \% ; P<0.05)$. NSE extracts did not significantly affect TC. Glibenclamide significantly $(P<0.05)$ lowered TC by $38 \%$ than that of initial concentrations. Even though TC levels were significantly lowered (123.75 $\pm 2.80 \mathrm{mg} / \mathrm{dL}$ ) by glibenclamide, these were higher than that of the vehicle group $(54.67 \pm 7.64 \mathrm{mg} / \mathrm{dL})$. About $1.3-3.38 \%$ change in HDL-C as compared to the respective baseline measurements by NSM and NSE was quite insignificant. Contrary to that, a decline in initial LDL-C levels by NSM and NSE was noteworthy $(P<0.05)$. Nonetheless, more profound changes in high dentistry and low-density lipoprotein cholesterol were

\section{Pancreatic histopathology:}

The microanatomical changes in the pancreatic tissues are presented in Figure 1 (A-E). Typical acini and normal cellular population were present in the islets of langerhans of the vehicle group (A). Alloxan monohydrate injection resulted in varying degree of damage to islet cells. Regular arrangement of cells was disturbed. Clumping, degranulation and hydropic degeneration were apparent in B-cells (B). Glibenclamide treatment caused partial regeneration of pancreatic beta cells (C) and NSM treated group had some survival B-cells (D) but not by NS ethanol extracts (E). Pancreas of glibenclamide treated group showed beta cells with normal granulations. Pancreatic anatomy of NSM and NSE groups did not match either with that of vehicle or diabetic group.

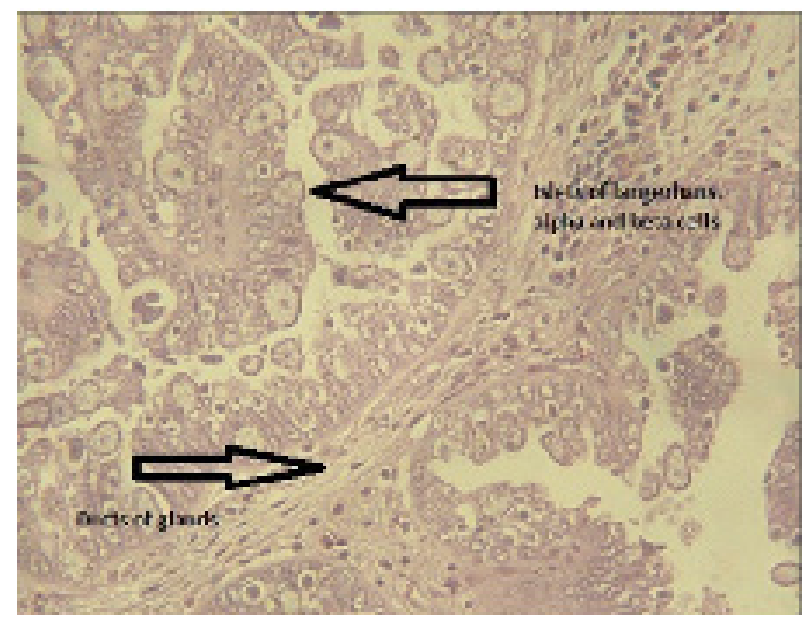

A

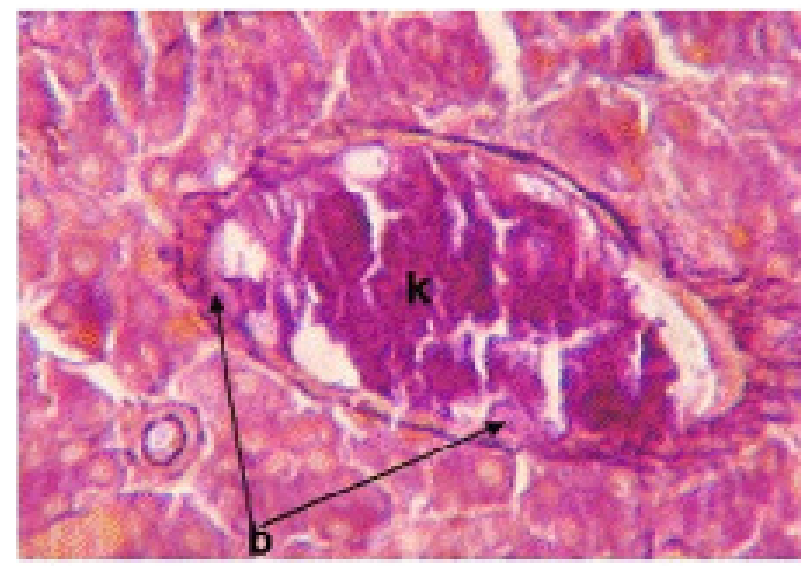

c

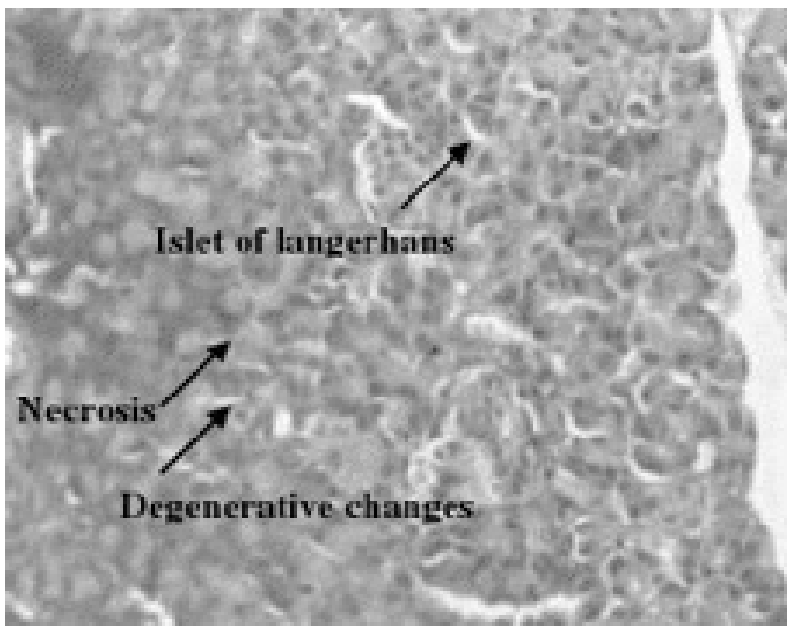

B

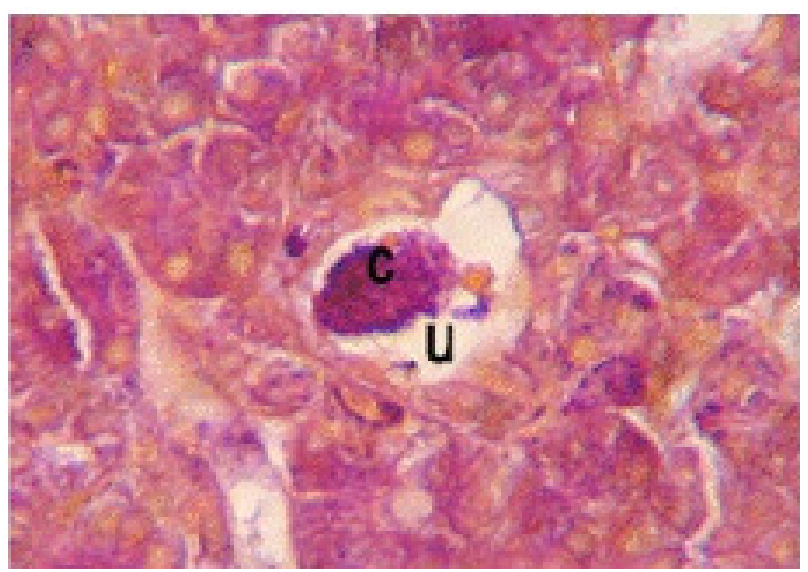

D 


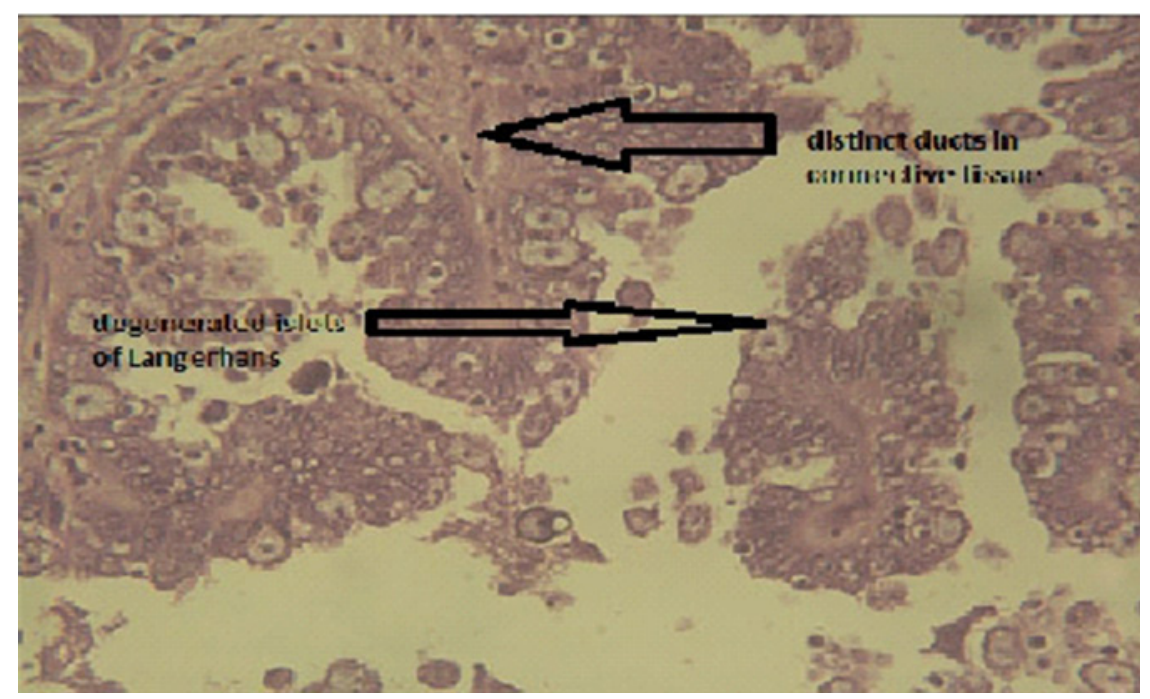

E

Figure 1. Histopathological sections of pancreas stained by chromium Haematoxyline-phloxine (A) pancreas of normal healthy rabbit with normal appareanace of islets of langerhans; (B) pancreas of diabetic rabbit showing degenerative changes and necrosis; (C) pancreas of diabetic rabbit, treated with NS methanol extract with aggregates (shrunken mass) of cells (k) and few survivor beta cells (b) at the periphery; (D) pancreas of diabetic rabbit, treated with NS ethanol extract. The distorted beta (c) cells of islets and degeneration (u) are highlighted by deeply stained and white areas respectively; $(E)$ pancreas of diabetic rabbit, treated with glibenclamide showing partial beta cells regeneration.

\section{DISCUSSION}

\section{Hypoglycaemic Effects:}

These observations were not supported by the findings of Al-Awadi and Gumaa. ${ }^{20}$ Likewise; Meral et al. observed that despite a major decline in elevated glucose concentration by NS, these levels were still higher $(194.41 \pm 27.33 \mathrm{mg} / \mathrm{dL})$ than those of the control animals $(96.32 \pm 8.37 \mathrm{mg} / \mathrm{dL}) .{ }^{21}$ Kaleem et al. and Bamosa et al. reported significant reductions in fasting blood glucose by NS in diabetic conditions.3,9 In a prospective study, Najmi et al. observed that NS oil (2.5 ml twice/day) rectified fasting glucose levels. ${ }^{22}$ The hypoglycaemic mechanism of NS, which is apparent in this study may be either through hepatic gluconeogenesis (Farrah et al.) or certain extrapancreatic changes (El-Dakhakhny et al.). ${ }^{23,24}$ An indirect hypoglycaemic nature of NS intervened by extrapancreatic actions was suggested by ElDakhakhny et al. ${ }^{24}$ Extrapancreatic mode of action can be explained by the presence of insulin -like peptides or glucose absorption inhibitory potentials of NS..$^{24,25,26}$ Conversely, some studies pointed towards beta cells regeneration, enhancement of insulin secretion and hypoglycemia by NS administration. ${ }^{27,28}$

\section{Hypolipidaemic Effects:}

Sabzghabaee et al. reported reductions in TG, TC and LDL-C by NS capsules ( $2 \mathrm{~g} /$ day) in Iranian subjects. ${ }^{11}$ Conversely, no change in HDL-C was apparent. In another study (Al-Logmani and Zari), NS reduced TG, TC and LDL-C and increased HDL-C in experimental animals. ${ }^{29}$ Similarly, when $800 \mathrm{mg} / \mathrm{kg}$ Nigella sativa oil was given orally to rats for four weeks, it significantly decreased TG, TC and LDL-C and increased serum
HDL-C levels. ${ }^{24}$ Le et al. studied the effect of petroleum ether extract of NS (equivalent to $2 \mathrm{~g} / \mathrm{kg} /$ day) on blood lipids in the normal rat. NS-treated rats had lower fasting plasma levels of triglycerides and higher HDL-C as compared to controls. ${ }^{2}$ Tasawar et al. found NS ( $500 \mathrm{mg} /$ day) treatment lowered cholesterol, LDL, VLDL and triglycerides in coronary artery disease patients. ${ }^{30}$ Administration of $5 \%$ NS oil to diabetic rats decreased lipid profile and elevated HDL-cholesterol level as compared to untreated diabetic rats. ${ }^{29} \mathrm{In}$ another prospective study (Najmi et al.), NS oil $(2.5 \mathrm{ml}$ twice/day) amended TC and LDL-C levels. ${ }^{22}$ Literature indicates the dose-dependent hypolipidaemic effect of N. sativa. Higher doses of NS, suitable solvent and longer treatment durations are most likely to induce pronounced hypolipidaemic effects. Results of the present study are partially in accordance with the previous data. ${ }^{3,4}$

\section{Pancreatic histopathology:}

Several studies are available on restoration of beta cells of islets of the pancreas by NS.2,9,10,11,13,28,29 Some phytochemicals liable for pancreatic cells renewals were either deficient in our preparations or proper solvent and treatment times were required for conspicuous histopathological changes.

\section{CONCLUSION}

N. sativa seed extracts exhibited significant hypoglycaemic and hypolipidaemic potentials. However, extracts did not show substantial beta cells regeneration activities. Further investigations are suggested to ascertain the therapeutic role of N. sativa in diabetes mellitus. 


\section{REFERENCES}

1. Coman C, Rugina OD, Socaciu C. Plants and natural compounds with antidiabetic action. Notulae Botanicae Horti Agrobotanici Cluj-Napoca 2012; 40:314-25.

2. Le PM, Benhaddou-Andaloussi A, Elimadi A, et al. The petroleum ether extract of Nigella sativa exerts lipid-lowering and insulin-sensitizing actions in the rat. J Ethnopharmacol 2004; 94:251-9.

3. Kaleem M, Kirmani D, Asif M, et al. Biochemical effects of Nigella sativa $L$ seeds in diabetic rats. Indian J Exp Biol 2006; 44:745-8.

4. Kocyigit $Y$, Atamer $Y$, Uysal E. The effect of dietary supplementation of Nigella sativa L. on serum lipid profile in rats. Saudi Med J 2009; 30:893-6.

5. Butt MS, Sultan MT. Nigella sativa: reduces the risk of various maladies. Crit Rev Food Sci Nutr 2010; 50:654-65.

6. Bourgou S, Pichette A, Lavoie S, et al. Terpenoids isolated from Tunisian Nigella sativa L. essential oil with antioxidant activity and the ability to inhibit nitric oxide production. Flavour and Fragrance Journal 2012; 27:69-74.

7. Shuid AN, Mohamed N, Mohamed IN, et al. Nigella sativa: A potential antiosteoporotic agent. Evid Based Complement Alternat Med 2012: 696230. Available at: http://www.hindawi.com/ journals/ecam/2012/696230/

8. Ahmad M, Qureshi R, Arshad M, Khan MA, Zafar M. Traditional herbal remedies used for the treatment of diabetes from district Attock(Pakistan). Pakistan Journal of Botany 2009; 41:2777-82.

9. Bamosa AO, Kaatabi H, Lebdaa FM, Elq AM, AlSultan A. Effect of Nigella sativa seeds on the glycemic control of patients with type 2 diabetes mellitus. Indian J Physiol Pharmacol 2010; 54: 344-54.

10. Balaha MF, Tanaka H, Yamashita H, Abdel Rahman MN, Inagaki N. Oral Nigella sativa oil ameliorates ovalbumin-induced bronchial asthma in mice. Int Immunopharmacol 2012; 14:224-31.

11. Sabzghabaee AM, Dianatkhah M, Sarrafzadegan $\mathrm{N}$, Asgary S, Alireza G. Clinical evaluation of Nigella sativa seeds for the treatment of hyperlipidemia: a randomized, placebo controlled clinical trial. Med Arh 2012; 66:198-200.

12. Kanter M, Akpolat M, Aktas C. Protective effects of the volatile oil of Nigella sativa seeds on betacell damage in streptozotocin-induced diabetic rats: a light and electron microscopic study. J Mol Histol 2009; 40:379-85.

13. Abdelmeguid NE, Fakhoury R, Kamal SM, Al Wafai RJ. Effects of Nigella sativa and thymoquinone on biochemical and subcellular changes in pancreatic $B$-cells of streptozotocin-induced diabetic rats. J Diabetes 2010; 2:256-66.

14. Benhaddou-Andaloussi A, Martineau L, Vuong T, et al. The in vivo antidiabetic activity of Nigella sativa is mediated through activation of the AMPK pathway and increased muscle Glut4 content. Evid Based Complement Alternat Med
2011: 538671. Available at: http://www.hindawi. com/journals/ecam/2011/538671/abs/

15. Abdel-Hamid NM, Abdel-Ghany MI, Nazmy MH, Amgad SW. Can methanolic extract of Nigella sativa seed affect glyco-regulatory enzymes in experimental hepatocellular carcinoma? Environ Health Prev Med 2013; 18:49-56.

16. Brown CA, Chan SLF, Stillings MR, Smith SA, Morgan NG. Antagonism of the stimulatory effects of efaroxan and glibenclamide in rat pancreatic islets by the imidazoline, RX801080. Br J Pharmacol 1993; 10: 1017-22.

17. Friedewald WT, Levy RI, Fredrickson DS. Estimation of the concentration of lowdensity lipoprotein cholesterol in plasma, without use of the preparative ultracentrifugation. Clin Chem 1972; 18:499-502.

18. DeLong DM, DeLong ER, Wood PD, Lippel K, Rifkund BM. A comparison of methods for the estimation of plasma low- and very low-density lipoproteun cholesterol: the Lipid Research Clinics Prevalence Study. J Am Med Assoc 1986; 256:23727.

19. Singh N, Gupta M, Sirohi P, Varsha. Effects of alcoholic extract of Momoradica charantia (Linn.) whole fruit powder on the pancreatic islets of alloxan induced diabetic albino rats. J Environ Biol 2008; 29:101-6.

20. Al-Awadi FM, Gumaa KA. Studies on the activity of the individual plants of an antidiabetic plant mixture. Acta Diabetol Lat 1987; 24:37-41.

21. Meral I, Donmez N, Baydas B, Belge F, Kanter M. Effect of Nigella sativa L. on heart rate and some haematological values of alloxan-induced diabetic rabbits. Scand J Lab Anim Sci 2004; 31: 49-53.

22. Najmi A, Nasiruddin M, Khan RA. Effect of Nigella sativa oil on various clinical and biochemical parameters of insulin resistance syndrome. Int J Diab Dev Ctries 2008; 28:11-14.

23. Fararh KM, Atoji Y, Shimizu Y, et al. Mechanisms of the hypoglycaemic and immunopotentiating effects of Nigella sativa L. oil in streptozotocininduced diabetic hamsters. Res Vet Sci 2004; 77: 123-9.

24. El-Dakhakhani M, Mady NL, Halim MA. Nigella sativa L. oil protects against induced hepatotoxic ity and improves serum lipid profile in rats. Arzneimittel-forschung 2000; 50:832-6.

25. Gray AM, Flatt PR. Insulin - releasing and insulin -like activity of the traditional antidiabetic plant Coriandrum sativum (coriander). $\mathrm{Br}$ J Nutr 1999; 81:203-8.

26. Meddah B, Ducroc R, El-Abbes Faouzi M, et al. Nigella sativa inhibits intestinal glucose absorption and improves glucose tolerance in rats. J Ethnopharmacol 2009; 121:419-24.

27. Kanter M, Meral I, Yener Z, Ozber H, Demir H. Partial regeneration/proliferation of the $B$-cells in the islets of Langerhand by Nigella sativa L. in streptozotocin-induced diabetic rats. Tohoku J Exp Med 2003; 201:213-9.

28. Rchid H, Chevassus H, Nmila R, et al. Nigella sativa seed extracts enhance glucose-induced 
insulin release from rat-isolated Langerhans islets.

Fundam Clin Pharmacol 2004; 18:525-9.

29. Al-Logmani A, Zari T. Long-term effects of Nigella sativa L. oil on some physiological parameters in normal and streptozotocin-induced diabetic rats. J Diabetes Mellitus 2011; 1:46-53.

30. Tasawar Z, Siraj Z, Ahmad N, Lashari MH. The effects of Nigella sativa (Kalonji) on lipid profile in patients with stable coronary artery disease in Multan, Pakistan. Pakistan Journal of Nutrition 2011; 10:162-7. 